\title{
O Corpo Gordo na Revista Veja: uma análise discursiva
}

\author{
The Fat Body on Veja Magazine: a discoursive analysis
}

Tânia Augusto PEREIRA*

Resumo: Neste artigo, objetivamos investigar o discurso da revista Veja diante do "combate" à obesidade, para alcançar o corpo magro, tido como o ideal, e quais efeitos de sentido são construídos no discurso apresentado sobre o corpo gordo. Para isso, selecionamos como corpus de análise duas capas da revista Veja. Nosso texto está embasado nos dispositivos teórico-metodológicos da Análise do Discurso francesa. Neste campo teórico, o discurso, entendido como "estrutura e acontecimento", situa-se em uma dupla dimensão: a linguística e a sócio-histórica. Por isso, sua interpretação não pode prescindir a memória discursiva.

Palavras-chave: Análise do Discurso. Revista Veja. Corpo. Memória discursiva.

Abstract: In this article, we investigate the discourse of $V e j a$ magazine on the "battle" with obesity to achieve a thin body, seen as the ideal, and what effects the way the covers trigger the speech delivered on the body fat. To this end, we selected the corpus of analysis covers two of Veja magazine. Our text is grounded in theoretical and methodological devices of French Discourse Analysis. In this field theoretical discourse, understood as "structure and event," lies in two dimensions: the linguistic and socio-historical. Therefore, its interpretation cannot ignore the discursive memory.

Key-words: Discourse Analysis. Veja Magazine. Body. Memory discursive.

\footnotetext{
* Doutorado em Linguística pela Universidade Federal da Paraíba, em João Pessoa, PB. Professora de Linguística do Departamento de Letras e Artes da UEPB, campus I, em Campina Grande-PB. Contato: taniauepb@yahoo.com.br.
} 


\section{Comentários Iniciais}

“No princípio era o verbo". Mas ele, sozinho, não vendia muita revista e jornal, principalmente, em um mundo onde a luz se fez e as imagens resplandeceram com grande vigor. Em 1967, Caetano Veloso apresentou o movimento tropicalista ao Brasil com a música "Alegria, Alegria”, em apresentação ao vivo realizada no III Festival da TV Record. Na letra da canção, "O sol se reparte em crimes, espaçonaves, guerrilhas / em caras de presidentes / bomba e Brigitte Bardot / O sol nas bancas de revistas me enche de alegria e de preguiça", o cantor baiano já se perdia na oferta caleidoscópica de manchetes existente nas bancas de jornais. Hoje, com televisão, internet e outros meios de comunicação, torna-se cada vez mais difícil atrair um leitor para que ele pare, olhe e compre uma revista a partir da capa.

Pensando na função de "vitrine" que a capa de revista exerce para despertar a atenção dos leitores, objetivamos investigar: a) o discurso da revista Veja diante do "combate" à obesidade, para alcançar o corpo magro, tido como o ideal; b) quais efeitos de sentidos as capas desencadeiam no discurso apresentado sobre o corpo gordo.

Nosso texto está embasado nos dispositivos teórico-metodológicos da Análise do Discurso (AD), de orientação francesa, que nos possibilitam produzir saberes capazes de fazer refletir, inquietar através da análise dos discursos disseminados pela mídia na sociedade. Com um único enunciado, percorremos a história e conhecemos terras distantes através das relações discursivas. Neste campo teórico, o discurso está no social e implica a exterioridade à língua, já que as palavras estão impregnadas de aspectos sociais, históricos e ideológicos, expressos materialmente por meio da linguagem.

Nosso construto teórico será mobilizado a partir dos diálogos entre Pêcheux e Foucault, a partir da terceira fase da AD. As ideias de Foucault permitem múltiplas leituras em muitos campos do saber. Isso acontece porque ele interessou-se por vastas problemáticas relacionadas ao saber, ao poder e ao sujeito. Embora tendo como centro a figura do sujeito, ele investigou o discurso em lugares onde os saberes estabelecidos não alcançavam: o discurso dos loucos nos hospícios, dos criminosos nas prisões, enfim, os discursos do cotidiano eram seus objetos de análise. 
Interessa-nos aqui pensar o discurso a partir da "caixa de ferramentas conceituais" foucaultiana na busca de compreender a formação, a circulação, e a transformação das práticas discursivas relacionadas ao corpo, nosso objeto de investigação. Tais práticas têm natureza semiológica, são verbais e não verbais. Foucault, ao analisar os discursos, interroga as relações entre práticas discursivas e práticas histórico-sociais. Como ele próprio afirma,

[...] O que me interessa no problema do discurso é o fato de que alguém disse alguma coisa em um dado momento. Isto é o que eu chamo de acontecimento. Para mim, trata-se de considerar o discurso como uma série de acontecimentos, de estabelecer e descrever as relações que esses acontecimentos - que podemos chamar de acontecimentos discursivos - mantêm com outros acontecimentos que pertencem ao sistema econômico, ou ao campo político, ou às instituições. [...] Penso que há, em nossa sociedade e naquilo que somos uma dimensão histórica profunda e, no interior desse espaço histórico, os acontecimentos discursivos que se produziram há séculos ou há anos são muito importantes. Somos inextricavelmente ligados aos acontecimentos discursivos. Em certo sentido, não somos nada além do que aquilo que foi dito, há séculos, meses, semanas. (FOUCAULT, 2003 , p. 255-256, grifo do autor).

Na contemporaneidade, os discursos sobre o corpo tentam disciplinálo não mais como forma de punição, como demonstrou Foucault (2009) em suas análises da sociedade disciplinar, mas como forma de controle da população, que deve buscar o bem-estar físico e mental do indivíduo a qualquer custo. A maior atenção dedicada ao corpo e às práticas relacionadas a ele apenas reforçam e solidificam seu controle e dominação. É paradoxal a relação entre corpo e poder: quanto maior a atenção sobre o corpo, maior é o controle sobre ele.

Atualmente, há um discurso mercantil, de base econômica e mercadológica na mídia, que leva o sujeito a consumir comida calórica para que seja necessário o uso de produtos ligth e/ou diet, ou então fazer plásticas para ter o corpo cultuado na publicidade desses produtos. Há um investimento político dos corpos nos anúncios publicitários do tipo "como perder 7 cm em 10 dias"; "emagreça 5 quilos em dois meses". Assim, o sujeito é controlado sem perceber. Ele vai fazendo transformações no corpo 
para entrar na ordem do discurso midiático: “seja magro!" Esse discurso reafirma o ponto de vista de Foucault (2008, p. 147): “encontramos um novo investimento que não tem mais a forma de controle-repressão, mas de controle-estimulação: 'Fique nu... mas seja magro, bonito, bronzeado!..'

Analisar o discurso sobre o corpo a partir do campo da AD, com nuances foucaultianas, é convergir nosso olhar a horizontes maiores e apreendê-lo nas suas entrelinhas e na sua dimensão linguística e sócio-histórica. Para isso, utilizamos como corpus de análise duas capas da revista Veja. Mesmo não sendo considerada uma publicação especificamente de divulgação científica, esta revista colabora no processo de criação de uma mentalidade científica e de popularização da ciência em relação ao corpo ao se apropriar da concepção do corpo enquanto máquina, cuja "solução" só é possível pela crença no "verdadeiro" discurso da ciência. Este discurso pode ser traduzido muitas vezes pela divulgação das diversas maneiras de se cuidar do corpo.

Por ser a janela que conduz o leitor a um mundo ilustrado, a capa deve apresentar o tema central da publicação não apenas de forma séria, pois o leitor tem uma expectativa de emoção e a revista deve prometer isso. Nada de tédio, o que importa é o choque. A realidade deve ser estetizada para comunicar, um simples fato semanal deve ser apresentado ao leitor de forma espetacular, com imagens e cores vivas. A capa nega o caos do cotidiano social ao eleger o grande fato para o qual todos os outros devem se subordinar, hierarquizando o resto dos acontecimentos. Isso é parte de um ritual aguardado pelo leitor. Uma revista necessita de uma boa capa para auxiliar na conquista de leitores que a levem para casa, "precisa ser o resumo irresistível de cada edição, uma espécie de vitrine para o deleite e a sedução do leitor" (SCALZO, 2006, p. 62).

Escolhemos a revista $V e j a$ por ser um veículo de grande alcance no Brasil e credibilidade. Segundo o Instituto Verificador de Circulação, ela é a primeira no ranking de revistas mais lidas pelos brasileiros. A relevância dessa revista pode ser atestada pelo fato de que ela atinge um público considerável da classe média e porque é formadora de opinião. Ao se investigar a prática social envolvida na construção do discurso deste veículo midiático pode-se compreender melhor como se articulam os discursos e sua relação com as diversas práticas sociais na contemporaneidade.

Partindo do pressuposto de que todas as nossas crenças, todas as nossas verdades, vinculam-se de forma muito consistente aos padrões da 
sociedade e da cultura nos quais estamos inseridos, podemos considerar que aquilo que consideramos bonito e desejável, por exemplo, não se encontra dissociado das representações sociais sobre beleza. Uma das ideias mais poderosas que vem se popularizando ao longo dos últimos anos é aquela que diz que temos que ser magros para sermos considerados bonitos.

O corpo tem sobre si um grande exercício de poder. Nas palavras de Milanez (2006, p. 13),

... ele é o produto de uma subjetivação marcada por uma imagem que nos remete a uma forma temporal determinada, por isso, levo em conta os meios e as técnicas pelas quais elas se transmitem em nossa época em particular. O corpo subjetivado é a história de certa experiência do sujeito no mundo.

Em sua discussão sobre a analítica do poder, Foucault (2008) pontua a governamentalidade e reforça a análise de que um dos principais aspectos das sociedades modernas é a existência das técnicas de poder que disciplinam, monitoram, moldam e controlam o comportamento dos sujeitos sociais. Assim, a noção da biopolítica surge na vertente foucaultiana. Vista como um mecanismo de poder, a biopolítica intervém, sobretudo, para aumentar a longevidade da população, controlando seus acidentes eventuais. No caso específico da regulação da vida, o corpo foi encarado como o suporte de procedimentos biológicos feitos por intervenções e controles reguladores.

A partir dos anseios de cada sujeito, a fabricação dos corpos se torna possível por meio de intervenções plásticas, dietas, cosméticos, exercícios físicos, aplicações de substâncias específicas no corpo etc.. Foucault (2009) considera que o corpo é submetido a poderes que lhe impõem limitações, obrigações ou proibições, e tais discursos são proliferados em qualquer sociedade do mundo, visto assim, na nossa não poderia ser diferente. Segundo o filósofo francês,

Houve, durante a época clássica, uma descoberta do corpo como objeto e alvo de poder. Encontraríamos facilmente sinais dessa grande atenção dedicada então ao corpo - ao corpo que se manipula, se modela, treina, que obedece, responde, torna-se hábil ou cujas forças se multiplicam. (FOUCAULT, 2009, p. 117). 
No corpo encontramos as marcas do poder-saber, presentes na constituição do dispositivo de poder. Para um corpo ser útil torna-se necessário aplicar sobre ele um sistema de dominação e, para isso, impõem-se medidas disciplinares, sob formas de naturalizações, a partir de saberes estratégicos e eficazes. Assim, o corpo é visto como acontecimento, pois traz em si a presença do novo. Ao buscarmos em Foucault (2000, p. 26) a compreensão do "novo", observaremos que "o novo não está no que é dito, mas no acontecimento de sua volta", por isso o enunciado possui o seu caráter de singularidade mesmo quando repetido, atualizado, retomado.

Sobre a maneira como o trabalho discursivo das revistas influi na construção dos corpos dos sujeitos leitores, é pertinente considerar o ponto de vista de Milanez (2004) sobre a revista, entendida como um dispositivo de construção de identidades, porque serve à recriação de uma identidade que caracteriza uma experiência de alteridade para os leitores. Para o autor, a revista possibilita a constituição de corpos modelares e de objetos desejáveis.

Ser belo é estar de acordo com um padrão científico de normalidade, assim, ser normal significa não ser obeso, ter músculos definidos, conquistar a beleza, manter a juventude. As imagens que se repetem, incessantemente, nas capas das revistas aqui analisadas contribuem para a construção de um imaginário sobre a beleza, consequentemente do corpo magro, uma vez que os corpos divulgados estão sempre em construção e sempre prontos para serem desvelados pela ciência. Esta é posta como o conhecimento capaz de, metricamente, construir os corpos e proporcionar a felicidade, que não está mais no ser corpo, mas no ter um corpo conforme a nova ordem estética atual. Este corpo é colocado como parte de uma nova ordem estética em que todos devem se inserir, principalmente as mulheres. A ciência proporciona, então, a produção do corpo, cujas imagens nos transportam para o imaginário de que tudo é descartável e aquilo que não agrada pode ser desenhado conforme padrões pré-estabelecidos.

Neste sentido, o saber científico, na dimensão estética, serve como uma forma de conformar os corpos na sociedade e enquadrá-los em um padrão de normalidade dominado pelo discurso midiático, que se apropria do discurso científico veiculado nas revistas. Enfim, nesta dimensão percebe-se que o conhecimento da ciência e a aplicação de biotecnologias são fundamentais na construção estética contemporânea.

Este discurso contribui para a formação de crenças, estereótipos, idealizações sobre a construção de corpos perfeitos. A partir da configuração 
de novos paradigmas, esta realidade discursiva e biotecnológica (re)configura o corpo, estabelece novas relações sociais, cria e modifica a vida. Pode, enfim, resolver vários problemas ou ser uma ameaça para os sujeitos sociais. Neste horizonte, se configuram novas relações entre saber e poder, originando novas formas de reconfiguração dos corpos, segundo estratégias biopolíticas aplicadas à população, atuantes no controle, sujeição, criação e modificação da vida.

Pensar o corpo como Foucault é refletir acerca dos mais variados acontecimentos e inquietudes da modernidade. Era das mudanças, da adequação e da conformação dos corpos. Adequação no sentido de "estar sempre na moda", adquirindo hábitos que são vistos pelo senso comum como os melhores, os mais invejáveis e difíceis de seguir, mas que devem ser alcançados para a obtenção da "felicidade". Todas as manifestações corporais são resultados de constantes e meticulosas formas de investimento do poder sobre o corpo.

Na contemporaneidade, sob a égide da saúde, a sociedade é estimulada a combater o mal do século: o excesso de peso. $\mathrm{O}$ cerco à gordura aumenta. Assim, de maneira coercitiva, o sujeito é intimado a se enquadrar em programas de emagrecimento que exigem disciplina e persistência para adquirir um corpo magro. Esse corpo é o referente a ser alcançado não apenas em nome da estética, mas em nome da saúde.

\section{Corpo Gordo: normal ou anormal?}

A grande máxima socrática - "conhece-te a ti mesmo" - pode ser traduzida atualmente como "cuida-te a ti mesmo". Cuidar de si na pós-modernidade significa cuidar do corpo, sentir-se bem a partir de regras de conduta e de princípios impostos como verdades e prescrições, pela exposição incessante de imagem de corpos belos. Essa exposição midiática cria efeitos de sentido e opera na produção de verdades cristalizadas.

Dessa maneira, o sujeito é submetido a um mecanismo social disciplinar sobre seu corpo em diferentes contextos e suas escolhas são impostas por estratégias do poder. Em se tratando do corpo enquanto acontecimento discursivo espetacularizado, a mídia impõe um corpo magro, jovem e saudável à população brasileira, alicerçado por um discurso científico, ao mesmo tempo em que interdita outros, tais como o corpo gordo, o corpo magro anoréxico etc. Diante deste contexto, neste artigo pretendemos refletir 
sobre o corpo gordo, silenciado diante do dispositivo da magreza apresentado no discurso da revista $V e j a$.

Na ótica de Fischler (2005) e Le Breton (2010), o corpo cujas formas causam mal-estar social é o corpo transgressor. De acordo com Le Breton, no discurso estético, a transgressão está na deformação, no estranho, em corpos como o de Franskenstein, que é um corpo de vida e morte ao mesmo tempo. Para o sociólogo, estes corpos transgridem os limites do simbólico e de todas as leis que permitem nomeá-los, classificá-los, identificá-los. Nas palavras do autor,

... a condição do homem é corporal. Subtrair-lhe alguma coisa, ou lhe acrescentar, coloca esse homem em posição ambígua, intermediária. As fronteiras simbólicas são rompidas [...] toda modificação de sua forma engaja outra definição de sua humanidade. (LE BRETON, 2010. p. 64, grifo do autor).

Ao buscarem construir suas identidades, na sociedade contemporânea, os sujeitos estabelecem distinções sociais por meio das escolhas que formatam uma variedade de estilos de vida. Contudo, essas escolhas não são livres de pressões e limites impostos socialmente. O culto ao corpo constitui, na contemporaneidade, uma prática resultante de coerções sociais; basta lembrarmos as situações de desprezo e o desprestígio experimentado pelos obesos em nossa sociedade (FISCHLER, 2005).

Atualmente, o cuidar do corpo não tem a conotação ética adotada pelas sociedades estudadas por Foucault (2007). Hoje assistimos a um cuidado de si que não está a serviço da liberdade, mas corresponde à adaptação dos sujeitos à normatização da sociedade. Para Ortega (2008), as práticas ascéticas modernas fazem parte da biossociabilidade. Nesse novo paradigma, o biopoder tem no corpo um lugar privilegiado de ação. Ação que, na gestão da saúde, da longevidade, das performances corporais usa "o discurso do risco" como mecanismo no exercício do poder sobre o corpo social.

$\mathrm{Na}$ opinião do autor, os constantes discursos sobre a saúde e o corpo perfeito são resultantes da interação do capital com as biotecnologias e a Medicina. Os processos de subjetivação implicados nas novas práticas enfatizam os cuidados corporais, médicos, higiênicos e estéticos na construção das identidades. Segundo o autor, a ideia de que podemos moldar nossos corpos como quisermos está fazendo com que características como 
obesidade ou velhice passem a ser vistas quase como anormalidades. É como se só fosse idoso ou obeso quem não é responsável, quem não se cuida.

Além de discriminados, esses "novos desviantes" terminariam frustrados por não serem capazes de atingir o ideal socialmente imposto. $\mathrm{O}$ corpo é maleável, mas tem um limite. A propagação midiática de um ideal de maleabilidade total pode ser muito tirânica para os sujeitos que não conseguem atingi-lo. Seria ridículo dizer que devemos comer gordura como resistência, só porque dizem que não se pode fazer isso. Diante do paradoxo daqueles que se tornam escravos da saúde, o importante é ser saudável para fazer as coisas de que se gosta, e não para poder cuidar da saúde o tempo todo.

As estratégias de poder e de resistência afetam as formas de exercício do poder da vida cotidiana e classificam os indivíduos em categorias. Segundo Ortega (2005), os frequentes discursos sobre saúde e corpo perfeito são resultantes da união do capital com as biotecnologias e a Medicina. Os comportamentos, as escolhas dos alimentos, os cuidados com a saúde são norteados por um discurso que categoriza os indivíduos como responsáveis, vigilantes e bons e, ao mesmo tempo, por oposição, como irresponsáveis, desviantes e maus.

Através da legitimidade do discurso médico, os discursos sobre saúde incentivam o consumo de alimentos diets e lights, que apontam para a imagem de um corpo saudável, sem calorias extras, portanto "em forma". A obesidade, símbolo de distinção social em determinados períodos históricos, vista antes como metáfora de riqueza ou poder, na atualidade perde seu simbolismo em função de "riquezas qualitativas". Hoje, é a qualidade de vida, o bem-estar, a saúde e o corpo leve que são considerados.

$\mathrm{Na}$ sociedade atual, os meios de comunicação nos estimulam a comer e nos intimam à magreza, empurram-nos para os fogões com receitas para emagrecer. Contraditoriamente, exaltam a boa mesa e a dieta alimentar. É privilegiado um estilo de vida em que alimentos calóricos são cambiados em prol de alimentos menos calóricos, provocando o surgimento de um mercado paralelo que produz a quem pode pagar pela diferenciação. Legumes, frutas e verduras são produzidos sem agrotóxicos, e uma infinidade de produtos, fabricados com baixas taxas de calorias. Porém, a diferenciação tem um preço, e só pode usufruir de uma alimentação "melhor", quem pode pagar por ela. 
Gordura já rimou com formosura numa época em que o peso do corpo ainda não era um severo pesar. Seria errôneo supor que nossos antepassados acolhiam facilmente os obesos. Há séculos, repulsa e prestígio rondam os mais pesados e impõem regimes. Em seu mais recente livro, agora traduzido e publicado no Brasil, o historiador francês Georges Vigarello (2012) esmiúça os elogios e críticas que, desde o fim da Idade Média, fizeram do gordo uma figura impressionante, objeto de reprovações morais e estudos científicos.

Segundo o autor, no século XVIII surgiram graus de gordura e a ideia de que os mais gordos não representam apenas um excesso quantitativo e sim uma desordem. Passou-se a falar mais em obesidade do que em corpulência. A palavra obesidade, derivada do latim obesitas, surgiu nos dicionários franceses desse século, já relacionada à Medicina. Nessa época, o excesso de gordura passou a ser sinônimo de impotência. E se transformou em ocorrência mórbida no século XIX, quando diversos problemas respiratórios, digestivos e circulatórios foram associados ao obeso.

Sobre as várias histórias na trajetória milenar do gordo e do obeso, Vigarello (2012) afirma que, primeiramente existe a história moral, que atribui um comportamento transgressivo aos muito volumosos, como se sua gordura resultasse de uma gula incurável. Há ainda a suposição de que eles comeriam os alimentos que pertencem aos outros, transgredindo a ordem social. Em segundo lugar, existe a história estética do gordo, relacionada às categorias do belo e do feio. Em momentos de carestia, a saúde supõe barriga cheia e corpulência. Mas, há ainda uma história do interesse médico. Para a Medicina antiga, por exemplo, a saudável passagem dos humores entre as diversas partes do corpo podia ser obstruída pela gordura acumulada. Acreditava-se que seu excesso sufocava e enfraquecia.

No século XIX, o sentido da palavra obesidade ganhou em detalhamento e profundidade. A palavra passou a incluir fases avançadas do problema. Mas, também, houve uma dominação do critério estético. É este critério, sobretudo, que transformou a obesidade em algo recusado socialmente. As revistas femininas começaram a mostrar que o corpo exibido nas praias durante o verão podia trair as formas das roupas que o cobriam durante o inverno, a publicar artigos sobre dietas e exercícios e a destacar mulheres magras. Os anúncios publicitários associavam a magreza à jovialidade. O porte atlético e magro era ilustrado pelas revistas. No final do século XIX e no início do XX, a imagem do corpo magro foi promovida 
à exposição e aceitação midiática. Alguns corpos magros são interditados no discurso midiático. Entre eles, temos o corpo magro produzido por distúrbios alimentares, como bulimia - doença em que a pessoa provoca o vômito após as refeições - e anorexia - quando o indivíduo deixa de alimentar-se por considerar-se obeso.

Ainda de acordo com Vigarello (2012), o mais importante era o volume do corpo e não o seu peso. Nem todos sabiam o próprio peso, ele não fazia parte das identidades. Muitos se consideravam gordos quando não conseguiam fechar seus cintos e quando as roupas ficavam justas. No começo do século XX, algumas balanças foram instaladas nas estações de trem e, nos anos 1920, surgiu a valorização de uma magreza tonificada. Cresceram, desde então, os relatos sobre os problemas dos obesos, assim como o desejo de modificar suas formas físicas, inventando uma nova anatomia.

\section{O Corpo Gordo na Revista Veja}

Um dos aspectos mais perversos no processo de estigmatização do gordo é a noção propagandeada da existência de um corpo perfeito e de que é fácil ser adquirido, basta querer. Assim, o gordo possui um corpo indesejável numa sociedade que propaga todos os meios para se conseguir o corpo perfeito. Dentro de uma suposta neutralidade, e de uma legitimação pautada nas descobertas da Medicina, o discurso da revista Veja enfatiza a necessidade de o sujeito ser saudável, bastando para isso, "entrar em forma" e não apresentar os "quilos em excesso". Para se alcançar esse corpo os sujeitos são disciplinados, controlados. Desse modo, terão como recompensa um corpo, delineado, sem volume, esculpido como uma obra de arte.

A espetacularização do conteúdo midiático fez com que a mercadoria e o corpo se aproximassem cada vez mais, convertendo o mesmo em um bem de consumo. Ter um corpo "perfeito", "bem delineado", "em boa forma", significa a vitória sobre a natureza, o controle do sujeito sobre seu próprio corpo. A gordura, a flacidez, o sedentarismo simbolizam a indisciplina, o descaso, a falta de controle. As pessoas são culpadas pelo fracasso do próprio corpo, o qual, sem dúvida, é vigiado e punido (FOUCAULT, 2009).

As manchetes das capas selecionadas tratam do corpo gordo, da obesidade. O conhecimento da ciência é posto como aquele que resolverá 
diversos problemas em relação à aparência física. Dentro de uma dimensão estética é abordado o que a ciência médica pode fazer. A ordem do discurso que impera nesta dimensão versa sobre mudanças de hábitos da vida moderna, na busca de combater a obesidade, com alimentação adequada e atividade física regular, além da ingestão de medicamentos adequados para combater a obesidade.

A Figura 1 exibe uma imagem no estilo "antes e depois". De um lado, isto é, "antes", uma mulher apresenta-se com fisionomia séria e com os braços cruzados para esconder as indesejáveis "gordurinhas". Do outro lado, ou seja, "depois", a mesma modelo, agora menos gorda e sorridente, exibe um corpo invejável. Nas duas versões, ela está apoiada no produto que possibilitou o suposto "milagre" dessa mudança corporal. A foto de capa comprova a tese de que a imagem vale por mil palavras.

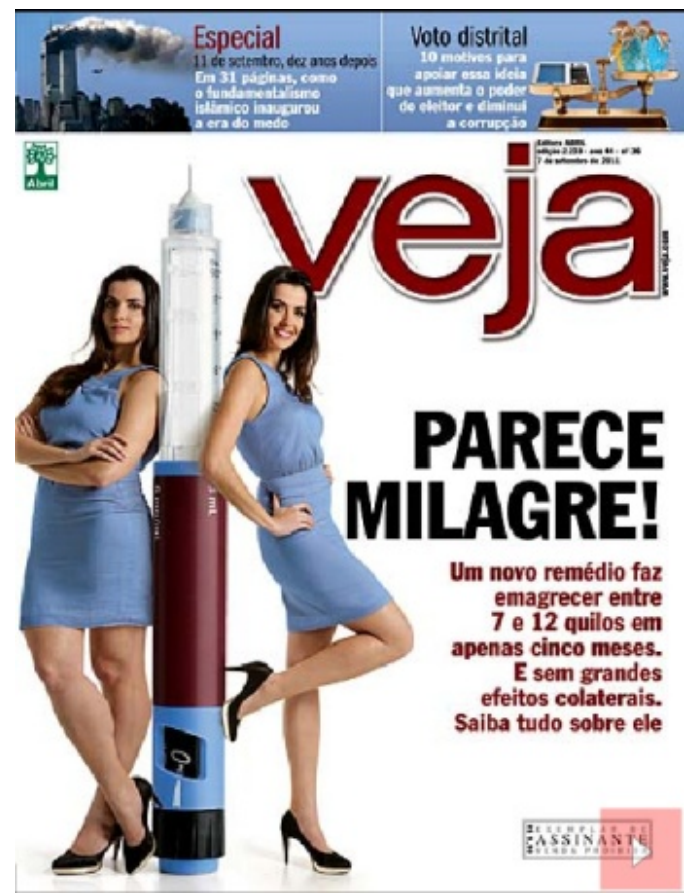

Fonte: Revista Veja, ed. 2233, 7 de setembro de 2011.

Figura 1 - Parece milagre! 
A reportagem da capa (Figura 2) divulga os progressos e novidades da Medicina no combate à gordura, apresentando uma versão científica sobre a obesidade e a receita científica para se obter um corpo magro. O uso de um novo remédio para emagrecer como aliado na perda do peso é o tema da matéria que tem como título "Menos sete, menos dez, menos doze quilos!” Esse enunciado legitima o que está dito na capa: “Um novo remédio faz emagrecer entre sete e doze quilos".

A imagem centralizada nas duas páginas mostra a transformação do corpo gordo em um corpo magro. A modelo apresentada na capa aparece novamente. Desta vez, ela surge com a fisionomia sempre alegre, feliz com os resultados obtidos com o uso do produto que provoca uma transformação "milagrosa" em seu corpo. Isso endossa o discurso da capa que anuncia o "milagre" resultante do medicamento.

Nas páginas da reportagem circulam informações sob o viés de um grupo socialmente constituído que expressa também um julgamento de valor, levando à apreensão dos fatos sob um prisma determinado, inapreensível à primeira vista e que direciona a construção dos sentidos. O discurso médico-científico se apresenta para legitimar o discurso midiático, é a "vOz dos especialistas". Toda a reportagem está alicerçada no fato de o remédio anunciado ser a melhor solução defendida pela ciência na luta contra a obesidade.

O texto começa afirmando: "É grande a probabilidade de você, leitor, se identificar com a história a seguir". E termina ponderando que a substância usada no novo remédio "pode ser considerada a bala de prata contra o excesso de peso". Entre os dois enunciados, o leitor tem à sua disposição sete páginas com entrevistas de endocrinologistas fazendo previsões sobre o novo remédio milagroso, depoimentos de pessoas que perderam peso ao usá-lo e, para não dizer que o texto só trata de dieta, há também um parágrafo abordando a situação dos diabéticos no Brasil e no mundo, já que o remédio anunciado é indicado também para diabéticos.

O que dá legitimidade a um discurso é o reconheci-mento daquele que diz como autoridade para dizê-lo, ou seja, não é qualquer um que pode dizer a qualquer outro qualquer coisa em qualquer lugar e em qualquer circunstância. Assim, a legitimidade na matéria ancora-se em dois pontos: a força da imagem de quem fala e a credibilidade do discurso do especialista, tido como competente e verdadeiro (discurso científico). 


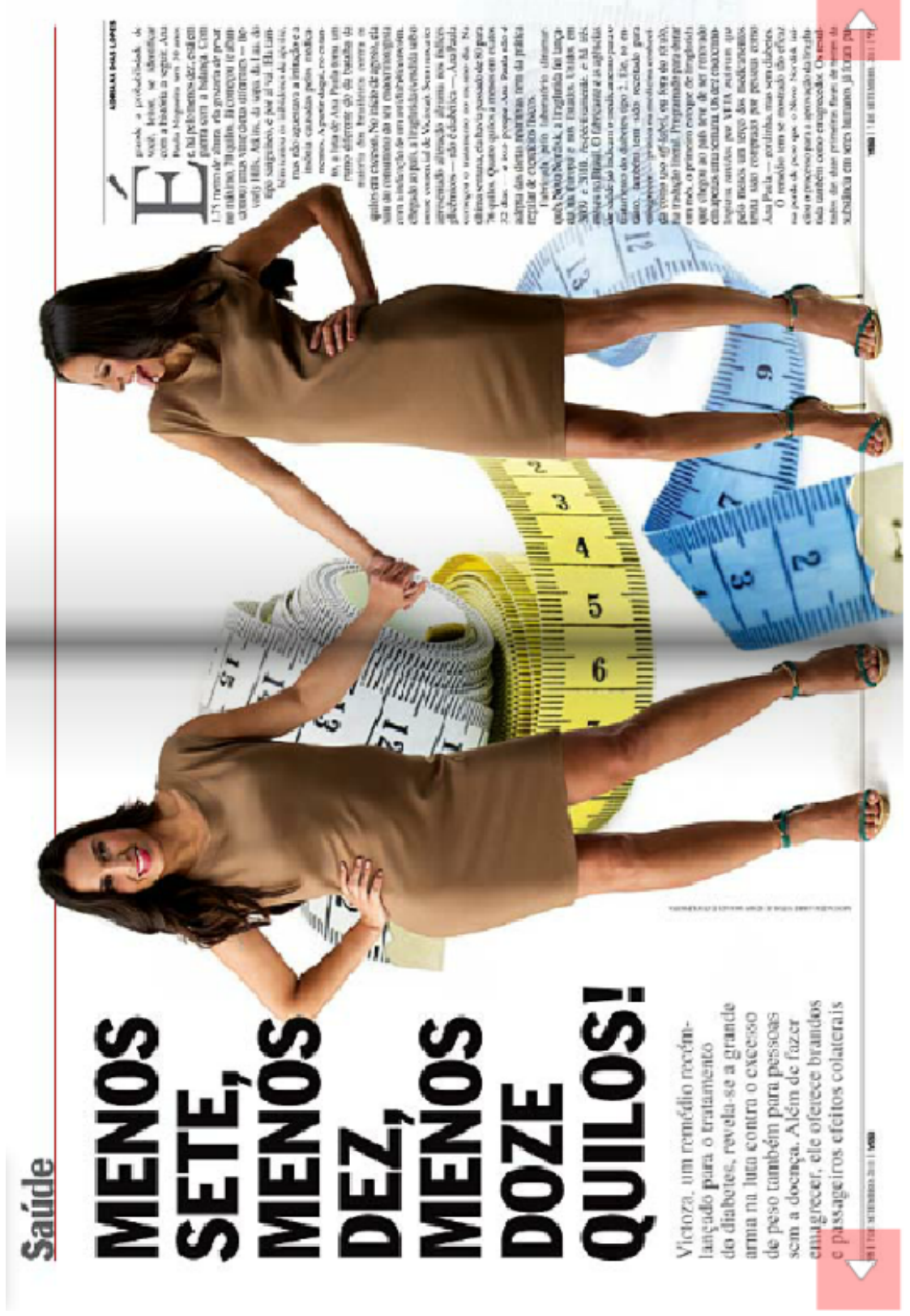

Fonte: Revista Veja, ed. 2233, 7 de setembro de 2011.

Figura 2 - Menos sete, menos dez, menos doze quilos! 
A legitimidade conferida pelo discurso dos espe-cialistas - médicos, nutricionistas e professores de educação física - está embasada no seu ilusório caráter de verdade absoluta, levando o sujeito a buscar nele a verdade para os seus próprios dizeres. Cabe considerar que os sujeitos leitores assumem e repetem como verdadeiro o discurso científico pelo fato de ele estar ancorado em um conhecimento considerado a priori legítimo, fazendo com que esse discurso se torne hegemônico e representativo das formas de pensar e de agir dos coletivos, aspecto no qual reside o poder e o controle social dessa formulação discur-siva.

$\mathrm{O}$ autor do discurso, como sujeito autorizado a falar, desenvolve sua argumentação, a fim de que ela soe como indiscutível, já que se apoia simultaneamente na "mudança" e na tradição. Esse autor, que possui a capacidade técnica e científica que lhe dá o monopólio da autoridade, tem condições de impor as regras e a forma de acesso não só às regras como também à possibilidade da fala, pois "ninguém entrará na ordem do discurso se não satisfizer a certas exigências ou se não for, de início, qualificado para fazê-lo" (FOUCAULT, 2000, p. 36).

Comparando a capa da revista $V e j a$ que circulou em 2011, na primeira década do século atual, com outra capa (Figura 3) que circulou nos anos 1900 do século passado (edição 1472 de 27 de novembro de 1996), identificamos uma narrativa visual que se apoia na memória, concernente à existência histórica do enunciado, que implica a retomada no presente de um enunciado produzido no passado. Considerando que o discurso faz parte de uma teia discursiva, o enunciado da capa na Figura 3 aciona o discurso da capa anterior, não apenas retomando-o, mas também possibilitando o apagamento de outros discursos que também significam.

Como a gordura é considerada o mal da década de 1990, a revista Veja exibe na capa a manchete: "Gordura tem remédio". A matéria principal apresenta "as novas drogas que combatem a obesidade". A capa destaca uma mulher usando um maiô que realça o seu corpo magro e esguio. Ela está entre cápsulas de medicamentos que aparecem, metaforicamente, como se fossem balas que estivessem sendo "disparadas" em meio a um combate, cujo alvo é a gordura corporal. 


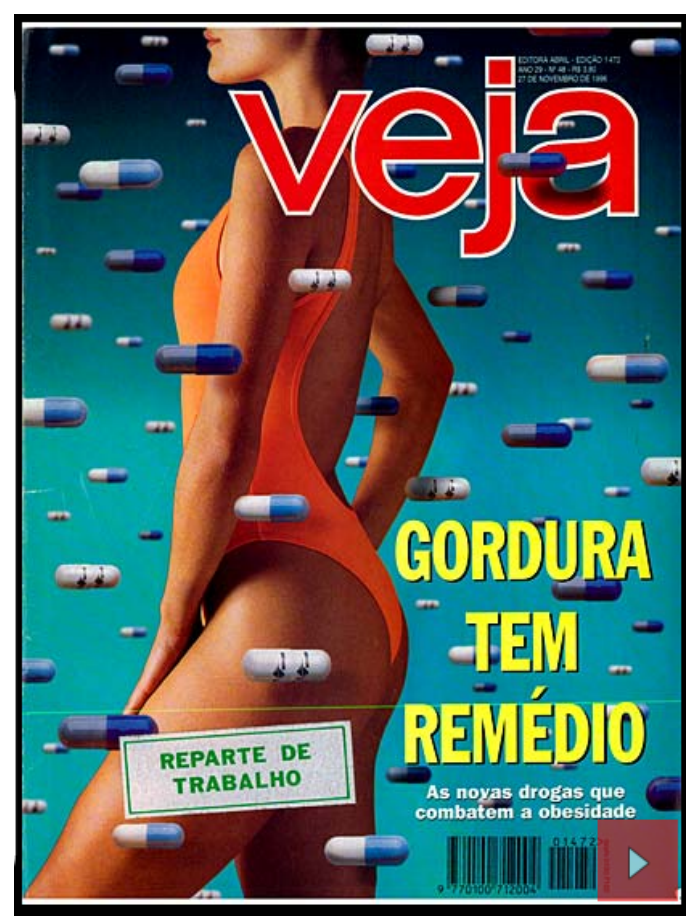

Fonte: Revista Veja, ed. 1472, 27 de novembro de 1996.

Figura 3 - Gordura tem remédio

A reportagem da capa utiliza um discurso bélico, no qual termos como "aliados", "guerra" contra gordura, "combate" à obesidade, entre outros, mostram que a revista trava uma grande batalha contra as calorias. A solução apontada para a perda de peso de um sujeito obeso é o uso de uma droga desenvolvida por cientistas americanos, o redux. Apoiada nos discursos médico e nutricional, a revista esclarece os benefícios gerados com o uso do novo remédio aliado à prática de atividades físicas e uma dieta calórica.

A matéria central apresenta ao leitor, que busca uma fórmula ideal para emagrecer, os novos remédios como "uma esperança a mais para os gordos decepcionados com os resultados das dietas e dos exercícios". Diante do "peso de perder peso", a revista mostra ao leitor algumas possibilidades para emagrecer: "apenas exercício; apenas dieta; dieta+exercício; remédio; 
dieta+remédio+exercício", esta última proposta considerada pela reportagem como a combinação ideal para a redução do peso.

Com a promessa de sanar os males estéticos, o remédio é oferecido aos corpos atormentados pelo excesso de peso e pela gordura. A responsabilidade do sujeito sobre o controle da gordura é transferida para o medicamento. Além do resultado eficiente, há o conforto do leitor, em especial a mulher, sua única atitude deve ser ingerir o remédio para obter um corpo perfeito, sem nenhum esforço físico - verdadeira promessa nirvânica. O poder concedido à solução farmacológica possibilita uma pausa na coerção corporal, liberando a mulher da vigilância calórica cotidiana.

Le Breton (2007, p. 23) opina que a Medicina interfere na natureza com a finalidade de dominar a vida e controlar a genética, "tornando-se uma instância normativa, um biopoder, uma forma científica e cruel de enunciação do destino". No discurso da revista Veja o corpo é pensado como um objeto indiferente, um simples suporte do indivíduo, tornando-se uma matéria-prima a ser retrabalhada, na qual a identidade se dilui, entre textos, imagens e recursos gráficos virtuais.

Ao pensar a memória como um espaço de deslocamentos, de polêmica, Pêcheux (1999, p. 53) defende que "sob o mesmo da materialidade da palavra abre-se então o jogo da metáfora, como outra possibilidade de articulação discursiva", de maneira que do já-dito, do já-significado possa brotar o novo, o acontecimento. Como afirma Ferreira (2008, p. 15), "a memória não movimenta sozinha a máquina dos sentidos”. O seu funcionamento se processa pelo entrecruzamento entre a sistematicidade da língua, a historicidade e a interdiscursividade.

$\mathrm{Na}$ dispersão dos enunciados existem regularidades nos acontecimentos discursivos, estabelecendo-se continuidades temáticas, segundo regras das práticas discursivas de determinado espaço e tempo. Observamos nas duas capas da revista $V_{e j a}$, enunciados que são retomados, temas que se repetem e que pertencem a um espaço e tempo definido. Destacamos alguns exemplos: remédios, drogas, emagrecer, obesidade, gordura.

Na sistematicidade da língua lidamos com suas regras, driblando suas normas e trabalhando sua engrenagem; na historicidade, temos a inscrição da história na língua e o movimento dos sentidos no texto, sustentando e orientando nossa interpretação do texto; na interdiscursividade, buscamos no repetível, no que já foi incessantemente dito, o material para ressignificar, produzir novos sentidos. 
Observando as similitudes entre as duas capas apresentadas, identificamos um diálogo entre elas que nos permite recuperar, no enunciado imagético do novo acontecimento discursivo, os efeitos de sentido do enunciado mais antigo. Esse diálogo de sentidos é reconhecido pela intericonicidade entre as duas imagens. Os sentidos produzidos pelos enunciados verbais e não verbais se combinam na história de maneira a produzir novas significações

$\mathrm{Na}$ produção dos sentidos, matéria-prima da análise dos discursos, que dão tessitura à linguagem, está presente a memória, operando na costura dos múltiplos fios, cheios de nós, às vezes, rompidos, às vezes, suturados. Como afirma Courtine (2006), a linguagem, "tecido da memória", se apresenta como aquilo que ora se costura, ora se esgarça, ora se esburaca. Nessa perspectiva, o autor pontua sobre a memória das imagens e considera que quando uma imagem é vista, outras são relembradas. Isso acontece com as duas capas analisadas; elas apresentam vestígios da memória discursiva, possibilitando o retorno e a atualização de temas e figuras do passado.

As capas mostram imagens visuais que, ao mesmo tempo, se associam a imagens sociais, estabelecendo uma rede de memória por meio de ligações entre as representações visuais e as construções sociais. As imagens são compreendidas como um espaço simbólico de significação e como lugares de interpretação para se pensar o corpo na sociedade midiática em que vivemos.

No acontecimento discursivo dessas capas estão presentes formulações linguísticas quase sempre marcadas por um enunciado recorrente, “corpo gordo". Diante disso, colocamos a seguinte questão: por que esse enunciado e não outro? (FOUCAULT, 2005). Para tentarmos responder este questionamento, é necessário determinar as condições históricas da existência ou possibilidade do enunciado que acontece, porque as capas, como lugares de memória, refletem as representações sociais sobre o corpo, indicam, difundem, sedimentam e legitimam os modos de pensar o corpo na sociedade em que são divulgadas.

As capas apresentam um ideal de beleza feminino. Um critério baliza este ideal nos corpos apresentados nas imagens: o peso. O ideal de beleza apresentado afasta-se dos corpos das mulheres reais que necessariamente não vão ao encontro dos parâmetros e critérios impostos na sociedade midiática atual. As imagens apresentam corpos que encarnam uma beleza irreal, porque distante dos corpos reais das mulheres. 


\section{Comentários Finais}

Neste estudo, foram considerados os discursos da revista $V e j a$, fonte de informação e de grande circulação nacional. Esta revista constrói sentido sobre o corpo interagindo com outros campos sociais para conferir legitimidade ao seu discurso. Nesse campo de elaboração de significados, que tem o poder de produzir discursivamente "saberes" sobre o corpo, se entrelaçam redes de memória, que estabelecem diálogos interdiscursivos.

Assim, saberes oriundos de outros campos - médico, científico, etc. - compõem uma equipe de consultores da revista: endocrinologistas, nutricionistas, cirurgiões-plásticos, professores de educação física; detentores de um "saber" especializado, que reúnem "conhecimento" acerca do corpo e emprestam suas vozes e competências na construção de uma fala de autoridade, definidora de uma "verdade" sobre o corpo, dando credibilidade ao discurso das publicações. Um dos grandes desafios da contemporaneidade é enfrentar o modelo estético imposto socialmente e atravessado pelo discurso midiático.

No nível da construção dos enunciados sobre o corpo, Veja exerce o controle assumindo o papel de um manual que apresenta técnicas disciplinares. Tais técnicas corporais permitem entender que cada movimento do corpo é cultural, faz parte do saber e é sancionado pelo poder; a forma como o sujeito utiliza o seu próprio corpo e se dispõe do corpo do outro, com ou sem o uso de instrumentos, está condicionada e regulamentada pelas relações de saber e poder, pelo social e histórico.

\section{Referências}

COURTINE, J-J. O tecido da memória: algumas perspectivas de trabalho histórico nas ciências da linguagem. Polifonia, Cuiabá, v. 12, n. 2, p. $1-13,2006$.

FISCHLER, C. Obeso benigno, obeso maligno. In: SANT'ANNA, D. B. de. (Org.) Políticas do corpo. 2. ed. Tradução Mariluce Moura. São Paulo: Estação Liberdade, 2005. p. 69-80.

FOUCAULT, M. A ordem do discurso. 12. ed. Tradução Laura Fraga de Almeida Sampaio. São Paulo: Edições Loyola, 2000. 
FOUCAULT, M. Diálogo sobre o poder. In: MOTTA, M. B. (Org.). Michel Foucault. Ditos \& Escritos. vol. IV. Rio de Janeiro: Forense Universitária, 2003. p. 253-266.

FOUCAULT, M. A arqueologia do saber. 7. ed. Tradução Luiz Felipe Baeta Neves. Rio de Janeiro: Forense Universitária, 2005.

FOUCAULT, M. História da sexualidade III: o cuidado de si. 9. ed. Tradução Maria Thereza Costa Albuquerque. Rio de Janeiro: Graal, 2007. FOUCAULT, M. Microfísica do poder. 25. ed. Tradução Roberto Machado. Rio de Janeiro: Graal, 2008.

FOUCAULT, M. Vigiar e punir: nascimento da prisão. 36. ed. Tradução de Raquel Ramalhete. Petrópolis: Vozes, 2009.

LE BRETON, D. Adeus ao corpo. 2. ed. Campinas: Papirus, 2007.

LE BRETON, D. A sociologia do corpo. 4. ed. Tradução Sonia M. S. Fuhrmann. Petrópolis: Vozes, 2010.

MILANEZ, N. A disciplinaridade dos corpos: o sentido em revista. In: SARGENTINI, V.; NAVARRO-BARBOSA, P. L. (Orgs.). Michel Foucault e os domínios da linguagem: discurso, poder e subjetividade. São Carlos: Claraluz, 2004. p. 183-200.

MILANEZ, N. As aventuras do corpo - dos modos de subjetivação às memórias de si em revista impressa. 2006. Tese (Doutorado em Linguística) - Universidade Estadual Paulista Júlio de Mesquita Filho, Araraquara.

MILANEZ, N. O corpo é um arquipélago: memória, intericonicidade e identidade. In: NAVARRO, P. (Org.). Estudos do texto e do discurso: mapeando conceitos e métodos. São Carlos: Claraluz, 2008. p. 153-179.

ORTEGA, F. O corpo incerto: corporeidade, tecnologias médicas e cultura contemporânea. Rio de Janeiro: Garamond, 2008.

ORTEGA, F. Da ascese à bio-ascese ou do corpo submetido à submissão ao corpo. In: RAGO, M.; VEIGA-NETO. A. As imagens de 
Foucault e Deleuze: ressonâncias nietzschianas. 2. ed. Rio de Janeiro: DP\&A, 2005. p.139-173.

PÊCHEUX, M. O papel da memória. In: ACHARD, P. et al. Papel da memória. Tradução José Horta Nunes. Campinas: Pontes, 1999.

REVISTA VEJA. Acervo digital. Disponível em: <www.veja.com.br/ AcervoDigital>. Acesso em: 20 jun. 2011.

SCALZO, M. Jornalismo de revista. São Paulo: Contexto, 2006.

VIGARELLO, G. As metamorfoses do gordo: história da obesidade no Ocidente. Tradução de Marcus Penchel. Petrópolis: Vozes, 2012.

Recebido em abril de 2013 Aprovado em agosto de 2013 